\title{
Water Purification from lons of Cadmium (II) Using a Bio-Plateau
}

\author{
Oksana Lapan ${ }^{*}$, Oleksandr Mikhyeyev'1, Svitlana Madzhd², Tetyana Dmytrukha², \\ Larysa Cherniak², Valentyna Petrusenko²
}

\author{
${ }^{1}$ Department of Biophysics and Radiobiology, Institute of Cell Biology and Genetic Engineering, National \\ Academy of Science of Ukraine, Kyiv, 03143, Ukraine \\ 2 National Aviation University, Kyiv, 03058, Ukraine \\ * Corresponding author's e-mail: ksenija.lapan@gmail.com
}

\begin{abstract}
The study was conducted with the purpose of experimentally developing the method of water purification from ions of cadmium (II) using a new design of a bio-plateau, which is based on the use of terrestrial plants. In order to construct the bio-plateau, the following chemically inert floating materials were used as the substrate: perlite, expanded clay, granular foam, vermiculite, cork, on top of which the seeds of higher terrestrial plants were placed. The experimental data showed that foam was the best of the tested substrates, and of plants - barley, oats, corn and rye. The constructed bio-plateau was placed into tanks with a solution of cadmium on the 9th day of incubation to study the cleaning efficiency of terrestrial plants on the aquatic environment. Determination of the residual concentration of cadmium was performed with the method of AAC at $\lambda=228.8$. As a result, it was found that rye showed the best sorption properties of the tested plants. The influence of additional aeration and $\mathrm{pH}$ of the medium on the degree of water purification was established. The highest treatment efficiency was observed in the variant of a bio-plateau with aeration and at a $\mathrm{pH}$ of 8-9. The study shows the possibility of using terrestrial plants for the phytoremediation of water bodies.
\end{abstract}

Keywords: phytoremediation, bio-plateau, terrestrial plants, cadmium (II).

\section{INTRODUCTION}

Taking into account the unsatisfactory condition of water objects, the task of their purification from cadmium ions, salts of which are contained in waste water from mining and processing plants, metallurgical, machine-building, metalworking, chemical, chemical-pharmaceutical, paint and varnish, textile, aircraft repair and other plants is urgent [10].

Traditionally, reagent purification methods have been used for the removal of cadmium from wastewater, the essence of which is to convert the water-soluble substances into insoluble substances when adding various reagents, followed by their separation from water in the form of precipitation $[11,7]$. However, wastewater treatment with the use of phytotechnologies has recently become widely used, which allows to improve the state of aquatic ecosystems and significantly reduce the flow of residual concentrations of heavy metals into water bodies $[2-4,9,15,11,14,17]$.

The main idea of the phyto-technologies is to filter wastewater through the thickets of higher aquatic plants and to use a specially selected sand and gravel filter with pre-deposition of suspended particles in the sedimentation tank. On this basis, a new type of surface water purification was developed, based on the use of ecosystem mechanisms, which was called "bio-plateau" in Ukraine, "botanical sites" in Germany, "reed bed" in Great Britain, etc. In the world scientific literature, the most common name for water treatment plants of this type is the term "Constructed Wetlands" or "Artificial Wetlands" $[1,6,16,13]$.

Previous studies have demonstrated [8] that not only higher aquatic plants are characterized by high accumulation rates, but also terrestrial 
plants in water culture have the same ability to accumulate toxic substances. The main advantages of this method are low energy consumption, high degree of purification, environmental friendliness and the ability to accumulate various types of pollutants.

The study was conducted with the purpose of the experimentally developing the method of water purification of cadmium (II) ions using a new design of a bio-plateau, which is based on the use of terrestrial plants.

The following tasks were set to achieve this goal:

- search for the species of terrestrial plants that can grow under the conditions of high humidity, and have a high ability to sorption of radionuclides;

- testing different types of substrates providing high buoyancy and close connection with the root system of plants;

- testing the substrates and plants for the forming of the floating bio-plateau;

- investigating the absorptive capacity of the bio-plateau with different species composition of plants relative to ions of cadmium (II);

- determining of the effect of extra aeration on the absorptive capacity of plants of the bio-plateau.

- studying the influence of $\mathrm{pH}$ environment on the sorption capacity of plants of the bio-plateau.

\section{MATERIAL AND METHODS}

\section{Design of the bio-plateau}

A variant of floating structure was proposed, the biotic component of which is ground plants, the mechanical strength of which is provided by the root system of plants. The essence of this technology is, firstly, in the use of terrestrial plants and, secondly, in the use of a substrate that is easily disposed of.

A search for terrestrial plants with a high coefficient of accumulation of cadmium was conducted. The ground plants were studied under the conditions of water culture; they showed high ability for heavy metal accumulation. Their ability to accumulate the metal ions from the aquatic environment is of great importance, since the ability to obtain the necessary amount of biomass of terrestrial plants is much higher than the similar ability of aquatic plants, which in turn can significantly improve the efficiency of water purification due to terrestrial plants. This was a prerequisite for the development of technology for cleaning polluted water bodies by using the sorption capacity of the root system of terrestrial plants grown in aquaculture. The use of intact higher ground plants is provided as a biosorption material. The plant material is an element of the biofilter, which is a system that uses the sorption properties of the root system of intact plants.

The seeds of rye seed (Secale), oat (Avena), maize (Zea mays) - the genera of annual herbaceous plants of the family of grasses (Poaceae); barley seed (Hordeum) is one or perennial plants of the family of grasses (Poaceae), meadow fescue (Festuca pratensis), meadow Timothy (Phleum pretense) which is a perennial plant of the family of grasses (Poaceae), flax (Linum usitatissimum) - an annual plant of the flax family (Linaceae); amaranth (Amaranthus) - a genus of herbaceous annual plants in the amaranth family (Amaranthaceae) were used for research.

The second stage in designing a bio-plateau was a search of the substrate for the development and growth of plants. The use of chemically inert floating materials was assumed: perlite, expanded clay, granular foam, vermiculite, cork. These substrates must meet a number of requirements:

- non-toxicity to plants;

- the minimum porosity to minimize the ingrowth of roots into the granules of the substrate;

- the ability to provide sufficient air exchange for seeds that germinate, in order to prevent the development of pathogenic microflora;

- relatively low cost.

The third stage in the construction of the floating bio-plateau was a combination of various seeds of different species of plants and substrate.

\section{The study of absorptive capacity of bio plateau}

The construction of the bio-plateau was carried out according to the following scheme: the cuvettes were used, $21 \times 2.5 \times 2.5 \mathrm{~cm}$ in size; the bottom of the cuvette was covered with a layer of foam $1.5 \mathrm{~cm}$ thick; a layer of agroperlite $\left(70 \mathrm{~cm}^{3}\right)$ was poured on top; $100 \mathrm{ml}$ of sedimented water was poured into the cuvette; the surface of the substrate was moistened with a spray; seeds were placed on the surface $\left(\mathrm{cm}^{3}\right)$ : rye $(25)$, oat 
(25) and barley (25) were placed in a thermostat at $\mathrm{t}=24^{\circ} \mathrm{C}$. After 9 days of germination of seeds, the bio-plateau was placed in desiccators with tap water (V=2.5 1), in which $\mathrm{CD}(\mathrm{II}), \mathrm{C}_{0}=1 \mathrm{mg} / \mathrm{l}$ were added. The samples of the solution $(20 \mathrm{ml})$ were taken on 6,14 and 22 days of incubation.

In order to determine the effect of extra aeration on the sorption capacity of the plant, the bioplateau was constructed by means of the standard method with the rye seeds. After 9 days of seed germination, the bio-plateau was placed in desiccators with tap water $(\mathrm{V}=2.51)$, in which $\mathrm{CD}(\mathrm{II})$, $\mathrm{C}_{0}=1 \mathrm{mg} / 1$ were added, and also provided additional round-the-clock aeration with the help of Regent Calm RC-004 pump, with a power of $2.7 \mathrm{~W}$. Samples of the solution $(20 \mathrm{ml})$ were taken on 6,14 and 22 days of incubation.

Next, six bio-plateaus with the seeds of oats were constructed. On the $9^{\text {th }}$ day of seed germination, a bio-plateau was placed in desiccators with water $(\mathrm{V}=2.51)$, different $\mathrm{pH}(3-10)$, which introduced $\mathrm{Cd}(\mathrm{II}), \mathrm{C}_{0}=1 \mathrm{mg} / \mathrm{l}$. On the $15^{\text {th }}$ day of incubation, the samples of the solution $(20 \mathrm{ml})$ were taken.

The degree of transpiration $(D T, \%)$ was calculated as follows:

$$
D T=\frac{\left(T_{0}-T_{p}\right)}{T_{0}} \cdot 100
$$

where $T_{0^{\prime}} T_{p}$ - respectively, the volume of water in the initial solution and in the solution after sorption, $\mathrm{ml}$.

Determination of the residual concentration of cadmium was performed with the AAC method [5] at $\lambda=228.8$.

The degree of purification from $\mathrm{Cd}(\mathrm{II})$ $(D P, \%)$ was calculated as follows:

$$
D P=\frac{\left(C_{0}-C_{p}\right)}{C_{0}} \cdot 100
$$

where $C_{\sigma^{\prime}} C_{p}$ - respectively, the concentration of $\mathrm{Cd}(\mathrm{II})$ ions in the initial solution and in the solution after sorption, $\mathrm{mg} / \mathrm{l}$.

\section{RESULTS AND DISCUSSION}

Studies have shown that in all variants of the combination of foam with crops such as oatmeal, corn, barley, oats, rye and timothy, a high degree of binding of the substrate to the root system and acceptable buoyancy of the bio-plateau were noted. Weak binding of the substrate to the root system was observed when combining vermiculite with oatmeal and vermiculite and amaranth. Both experiences had not provided the necessary buoyancy of the bio-plateau. The variants combining cork with oatmeal and flax showed a weak effect of binding the substrate to the root system, as a result of which the necessary density of the bioplateau was not achieved. When using expanded clay with oatmeal, a weak binding effect of the substrate and the root system was also observed, which is explained by the low buoyancy of the substrate itself.

Thus, the experimental data show that the best of the tested substrates turned out to be foam, and of plants - barley, oats, corn and rye. Figure 1 shows the result of growing corn on a substrate of granular foam. One can see the high density of a conglomerate of roots and foam granules .

In order to study the sorption capacity of plants relative to cadmium ions (Fig. 2) the cultures that

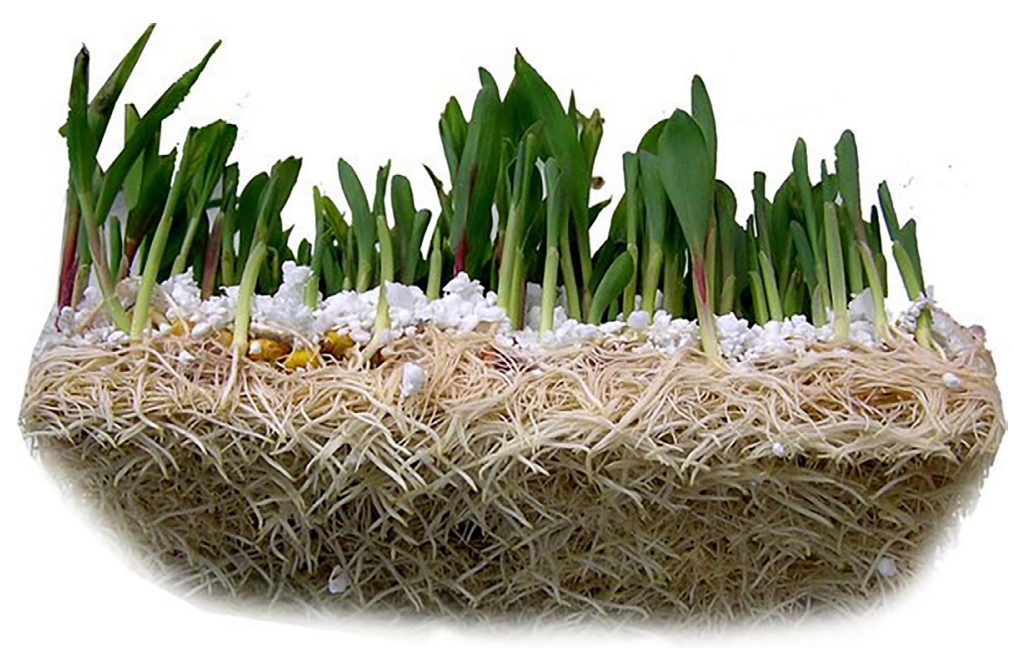

Fig. 1. Binding of the substrate by the corn root system 
met several criteria were selected: high rates of germination and development of the root system and the highest biomass. The root system of plants of barley, oats and rye firmly bound inert substrate of the bio-plateau.

It was found that on the sixth day of observation, the degree of purification of water from cadmium ions by means of rye plants was $56 \%$, which exceeded the indicators of purification by means of barley and oats $-52 \%$ and $38 \%$, respectively. On the $22^{\text {nd }}$ day of incubation of the bio-plateau on the solution, the concentration of cadmium cations decreased to $6 \%$, which was due to the sorption properties of rye. The degree of purification of the aqueous solution with barley and oats differed slightly - and amounted to $90 \%$ and $85 \%$, respectively.

Thus, the cultures of rye and barley demonstrated high sorption capacity with respect to cadmium (II) ions, so these plants were used in the following experiments. In order to study the effect of additional aeration on the degree of purification of the incubation environment, rye plants were used (Fig. 3), whereas barley plants (Fig. 4) were employed to investigate the effect of $\mathrm{pH}$.

It is seen that at all stages of observation, additional aeration contributed to more intensive absorption of cadmium (II) ions by rye plants. On the 19th day of incubation of bio-plateau on a solution with cadmium in the purification of water with supplemental aeration was $96 \%$, while without aeration, at $85 \%$.

There was a direct relation between the degree of purification and the degree of transpiration. It was also found that higher purification rates were observed at the $\mathrm{pH}$ of 8-9 solution, that is, in the embodiment of the medium with tap water, the $\mathrm{pH}$ of which is 8.6. The alkaline environment (within

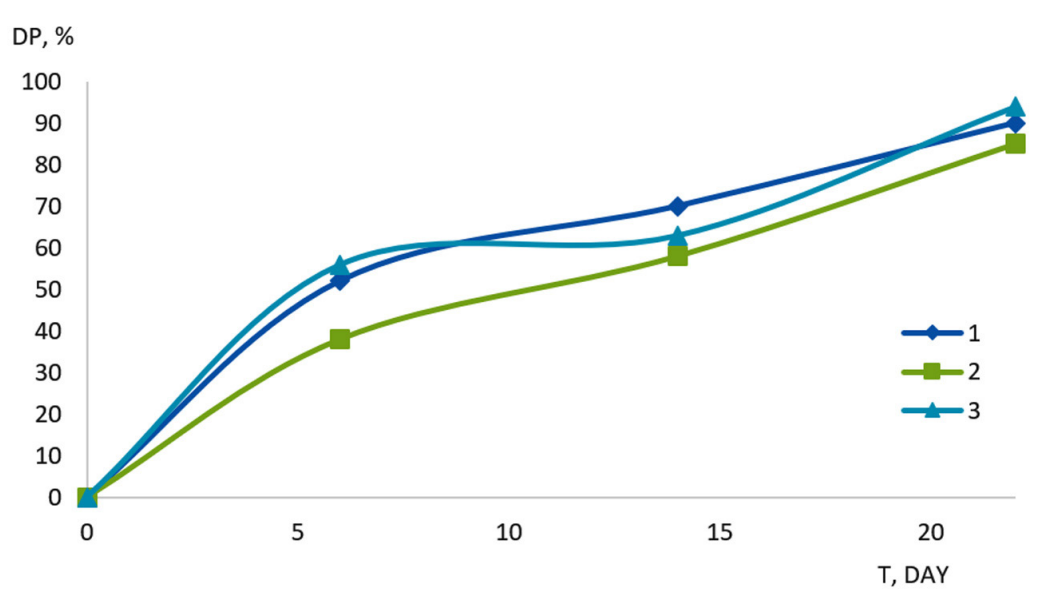

Fig. 2. Comparison of sorption capacity of plants with respect to cadmium (II) ions, $\mathrm{C}_{0}=1 \mathrm{mg} / \mathrm{l}: 1$ - barley, 2 - oats, 3 - rye

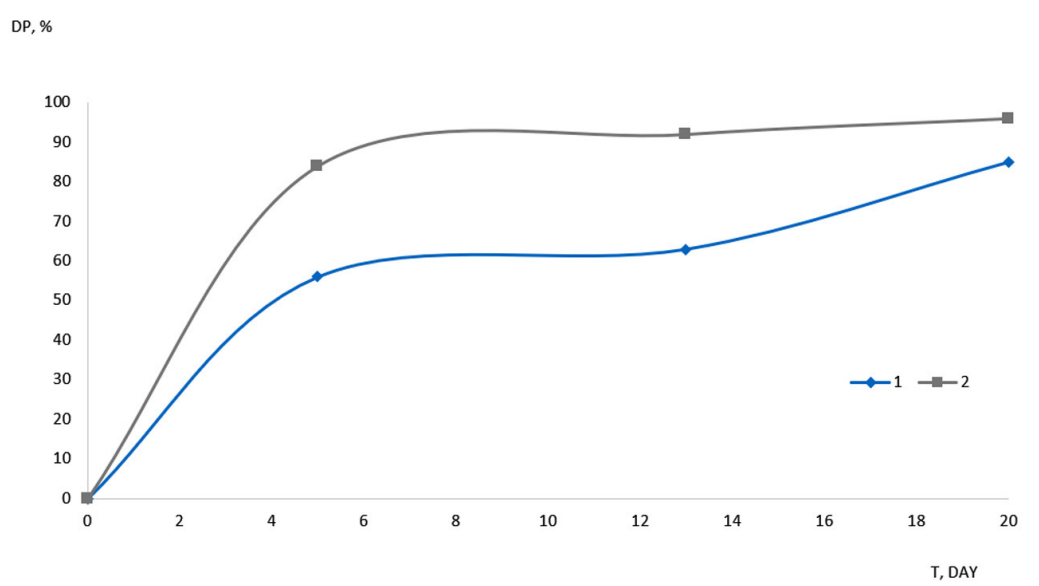

Fig. 3. The comparative sorption capacity of the bio-plateau without options (1)

(2) additional aeration, $\mathrm{C}_{0}(\mathrm{Cd})=1 \mathrm{mg} / \mathrm{l}$ 


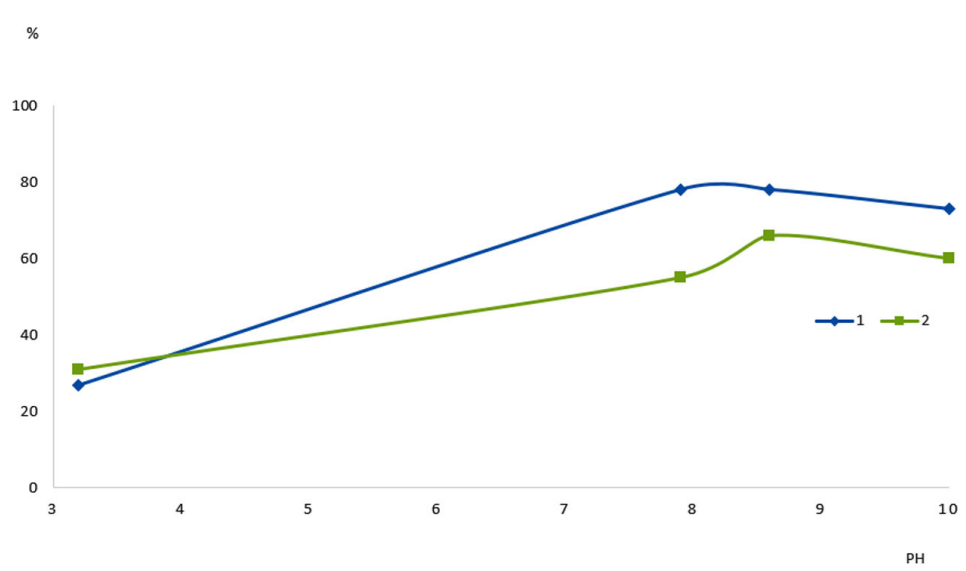

Fig. 4. Correlation between the degree of purification from cadmium ions $(\mathrm{CO}-1)$ and the degree of transpiration $(\mathrm{CT}-2)$ on the 15 th day of observation depending on the $\mathrm{pH}$ of the incubation environment

the $\mathrm{pH}$ range used) slightly inhibited the absorption of $\mathrm{Cd}(\mathrm{II})$ ions, in contrast to the acidic environment, for which a significant reduction in purification and transpiration levels was observed.

Thus, using the proposed design of bio-plateau will improve the ecological situation of the water techno-ecosystems.

\section{CONCLUSION}

A new method of constructing a floating bioplateau was developed, for the purification of the waters polluted with ions of cadmium, in which the terrestrial plants are the biotic component. The search for promising species of terrestrial plants that can grow normally under the conditions of water culture was carried out. It was shown that the best of such plants are: corn, barley, rye and oats. Several types of substrates were tested, as a result of which it was found that the granulated foam is the most optimal when using large-seeded plant species.

Under the conditions of a laboratory experiment using a bio-plateau, a high level of water purification from ions of cadmium (II) was achieved. It was also found that the $\mathrm{pH}$ of the environment and additional aeration influenced the purification parameters. The degree of water purification increased with the aeration option, and the acidic and alkaline environment inhibited the absorption of cadmium ions.

From the point of view of the bio-plateau application in real terms, we can say that it is proposed either to entirely withdraw the bio-plateau from the pond, followed by ashing (incineration) or produce periodic mowing of green mass of plants, which is also further subjected to ashing.

\section{REFERENCES}

1. Evdokimova G.A., Ivanova L.P., Mozgova N.P., Myazin V.A., Fokina N.V. 2016. Floating bioplato for purification of waste quarry waters from mineral nitrogen compounds in the Arctic. Journal of Environmental Science and Health, Part A, No. 51, 1-6. DOI:10.1080/10934529.2016.1181454

2. Glazunova I.V., Romashchenko A.K., Tishina K.A. 2018. Bioengineering structures and storage of local drainage of watersheds for the most effective use of water resources of river resources. Prirodoobustroystvo, 2, 46-54 [in Russion].

3. Filipchuk V.L., Bondar O.I., Kuriluk M.S., Ayaya A., Krivoshey P.P., Kuriluk O.M., Pochtar O.V. 2016. Water purification in filtration regenerative wetland. Bulletin NUWEE. 2(74), 193-204.

4. Filipchuk V.L., Kuriluk M.S., Filipchuk L.V., Kuriluk O.M., Krylyuk V.M., Pochtar O.V. 2016. Purification of muddy waters in filtration regenerative wetland. Bulletin of the Engineering Academy of Ukraine, 3, 150-155.

5. Khavezov I., Tsalev D. 1983. Atomno-absorbtsionnyy analiz, Leningrad, Khimiya, pp. 144 [in Russion].

6. Madzhd S.M. 2016. Experience in exploiting hydrophilic structures in Ukraine and in the world. Naukoiemni technologii, 2, 228-231 [in Ukrainian].

7. Madzhd S.M., Panchenko A.O., Bondar A.M. 2017. The role of higher aquatic plants in the degradation of pollutants in bioengineering hydrofit structures. Naukoiemni technologii, 1, 89-93 [in Ukrainian].

8. Mikheev, A.N., Lapan, O.V., Madzhd, S.M. (2018). Development of a new method of garment filtering purification of water objects of chrome (VI) Water Chemistry and Technology, 40(3), 309-314 [in Russion].

9. Nefedeva E.E., Sivolobova N.O., Kravtsov M.V., 
Shayhiev I.G. 2017. Purification of sewage with the help of phytoremediation. Vestnik tehnologicheskogo universiteta, 20(10), 145-148 [in Russion].

10. Ostrovskaya S.S. 2014. Токсичні ефекти кадмію. Visnyk problem biologii i medytsyny, 3(2), 33-37 [in Ukrainian].

11. Rоманенко В.Д., Крот Ю.Г., Киризій Т.Я. та ін. 2012. Natural and artificial biplane. Fundamental and practical aspects - К.: Наук. думка, p. 110 [in Ukrainian].

12. Shachneva E.Yu. Alykov N.M., Archibasova D.E. 2012. Adsorption of cadmium from aqueous solutions on modified sorbents. Tehnika i tehnologiya pischevyih proizvodstv, 4, 1-5 [in Russion].

13. Ülo Mander, Valdo Kuusemets, Märt Öövel, Raimo Ihme, Pertti Sevola \& Arnold Pieterse 2000. Experimentally constructed wetlands for wastewater treatment in Estonia, Journal of Environmental Science and Health, Part A, 35(8), 1389-1401, DOI: $10.1080 / 10934520009377042$
14. Ul'rih D.V., Bryuhov M.N. 2014. The ability to use phytoremediation facilities for wastewater treatment. Nauka YuUrGU: meterialy 66 nauchnoj konferentsii, 1050-1054 [in Russion].

15. Ul'rih D.V., Timofeeva S.S. 2016. Phytoremedia of contaminated soils and man-made soils of tailings in the territory of the Southern Ural Mining Companies. Gornyiy informatsionno-analiticheskiy byulleten (nauchno-tehnicheskiy zhurnal), 15, 341-349 [in Russion].

16. Yuriy Vergeles, Nataliya Butenko, Andriy Ishchenko, Felix Stolberg, Marika Hogland \& William Hogland (2016). Formation and properties of sediments in constructed wetlands for treatment of domestic wastewater, Urban Water Journal, 13(3), 293-301, DOI:10.1080/1573062X.2014.993178.

17. Zavatskiy S. V., Kotelchuk L. S., Kotelchuk A. L. 2012. Bioengineering structures for low-waste sewage treatment // Construction, engineering systems and communications, 1(3). 57-63. 